DOI: http://dx.doi.org/10.20435/multi.v21i49.606

\title{
Segurança do trabalho em serrarias
}

\author{
Occupational safety in sawmills
}

Zaíra Morais dos Santos Hurtado de Mendoza ${ }^{1}$

Pedro Hurtado de Mendoza Borges ${ }^{2}$

${ }^{1}$ Professora, Doutora, Departamento de Engenharia Florestal, FENF/ UFMT. E-mail: zaira@ufmt.br

${ }^{2}$ Professor, Doutor, Departamento de Solos e Engenharia Rural, FAMEVZ/UFMT. E-mail: pborges@ufmt.br 


\section{RESUMO ABSTRACT}

Objetivou-se com esta pesquisa fazer uma coletânea bibliográfica sobre segurança do trabalho em serrarias. 0 estudo foi desenvolvido com dados de vários "sites" de órgãos públicos e particulares, artigos científicos e revistas. A pesquisa mostrou que os perfis de acidentes dentro das indústrias madeireiras seguem um protótipo para todo o País, ou seja, não se diferencia de acordo com seus locais de origem. Vários acidentes de trabalho poderiam ser evitados pelo uso dos equipamentos de proteção. A qualificação da mão de obra operacional e a modernização do parque industrial também podem auxiliar na minimização desses acidentes. As serras circulares e de fita foram os equipamentos que mais causaram acidentes dentro das serrarias. 0 Estado de Mato Grosso, apesar de ser um grande polo madeireiro, não dispõe de normas regulamentadoras e disciplinadoras sobre segurança do trabalho em serrarias. Os acidentes de trabalho geram grandes custos para os cofres públicos.

\section{PALAVRAS-CHAVE}

Indústria madeireira segurança trabalhador
The objective of this research make a bibliographic collection on work safety in sawmills. The study was conducted with data from multiple "sites" of public and private agencies, scientific papers and magazines. Research has shown that accidents profiles within the timber companies follow a prototype for the whole country, that is, does not differ according to their places of origin. Several workplace accidents could be avoided by the use of protective equipment. The qualification of operating manpower and modernization of the industrial park can also help minimize these accidents. Circular and band saws are the equipment that caused the most accidents in the sawmill. The State of Mato Grosso, despite being a major hub timber, has no regulatory and disciplinary standards on work safety in sawmills. Work accidents create great cost to the public purse.

\section{KEY WORDS}

Timber industry

safety

worker 


\section{INTRODUÇÃo}

A exploração de produtos derivados da madeira é muito importante no contexto da sustentabilidade. Mercados externos como a Europa já não aceitam madeira proveniente de desmatamento e ilegalidades, solicitando aos fornecedores uma série de documentos que comprovem a origem da mercadoria e a legalidade de sua cadeia de produção. As empresas exportadoras já cumprem exigências abrangentes, como as estipuladas pelas certificações, que incluem regulamentações trabalhistas, de engajamento comunitário e uso da terra (ARAÚJO, 2014).

A agroindústria e as indústrias madeireiras são o setor mais importante na economia de Mato Grosso e a grande ocupação dessas indústrias no Estado está causando um impacto negativo no ambiente, sendo atualmente, considerado um dos Estados que mais desmatam dentro do Brasil por esse motivo. 0 País registrou em agosto 319 quilômetros quadrados de florestas degradadas (florestas intensamente exploradas pela atividade madeireira e/ ou queimadas) e a grande maioria (94\%) ocorreu em Mato Grosso, seguido por Rondônia (3\%) e Pará (3\%), ( , 2014).

No Estado, as madeireiras estão instaladas principalmente na região norte, noroeste e oeste de Mato Grosso, agrupadas em "Clusters" ou Polos. As principais "cidades-polos", que têm na atividade madeireira o seu fortalecimento econômico, são Sinop, em primeiro lugar, seguida de Aripuanã e Juara (PEREIRA, 2010).

Para atender às indústrias madeireiras que estão nesses grandes polos do Estado, a matéria-prima advém, em sua maioria, de florestas nativas, mas também de florestas plantadas, principalmente de eucalipto e teca. Notadamente, observa-se o crescimento do desmatamento e o aumento do número de madeireiras e serrarias que vêm surgindo com intuito de suprir o mercado nacional e internacional, porém a maioria de maneira ilegal, tanto com relação à implantação do empreendimento quanto na 
contratação da mão de obra. Isso faz com que ocorram trabalhos irregulares, sem autorização de órgãos competentes para poder operar e sem seguir as normas de segurança do trabalho, o que acarreta inúmeros acidentes (SILVA, 1999).

Com o intuito de orientar sob as Normas Regulamentadoras (NR) e Legislações vigentes, existem vários sindicatos estaduais que auxiliam aos empresários e colaboradores do setor madeireiro, tais como o Sindicato dos Madeireiros do Extremo Norte de Mato Grosso (SEMINORTE), Sindicato das Indústrias Madeireiras e Moveleiras do Noroeste de Mato Grosso (SIMNO), Sindicato das Indústrias Madeireiras do Norte de Mato Grosso (SINDUSMAD), Sindicato das Indústrias Madeireiras do Médio Norte do Estado de Mato Grosso (SINDINORTE), Sindicato das Indústrias Madeireiras do Vale do Arinos - Juara (SIMAVA), Sindicato dos trabalhadores na Indústria Madeireira do Estado de Mato Grosso (STIMAD), Sindicato dos Madeireiros de Sorriso (SIMAS), Sindicato das Indústrias de Base Florestal (SINDIFLORA), Comissão Interna de Prevenção de Acidentes (CIPA), Centro das Indústrias Produtoras e Exportadoras de Madeira do Estado de Mato Grosso (CIPEM) (FIEMT, s.d.).

Este trabalho teve como objetivo fazer uma coletânea bibliográfica sobre segurança do trabalho em serrarias, com destaque para as serrarias do Estado de Mato Grosso, visto que há falta de informação sobre esse tema.

\section{MATERIAL E MÉTODOS}

A pesquisa foi realizada na cidade de Cuiabá, MT, avaliando-se por meio de revisão bibliográfica, os seguintes tópicos: segurança do trabalho, ergonomia, perfil dos trabalhadores, tipos de riscos a que os trabalhadores estão sujeitos, equipamentos mais perigosos, EPIs na serrarias, Ministério do Trabalho e as legislações, segurança nas serrarias de Mato Grosso, estatísticas dos acidentes que ocorreram no Estado. 
Para levantamento da revisão de literatura, foram consultados bancos de dados de "sites" como IMEA, FAMATO, CIPEM, IMAZON, AREFLORESTA, IBGE, assim como revistas e artigos relacionados ao tema proposto.

\section{REVISÃO DE LITERATURA}

O conjunto de medidas colocadas em prática objetivando reduzir os acidentes ou mesmo riscos no trabalho, doenças ocupacionais, bem como cuidar da integridade e da capacidade de trabalho e do trabalhador pode ser entendido como segurança no trabalho (SILVA, 2008).

A segurança no trabalho foi surgindo aos poucos, devido à necessidade de se preservar a saúde física do trabalhador. De acordo com Marx (1996), o sistema capitalista de "quanto mais produzir significa mais dinheiro", é um exemplo que designa a Teoria da Mais-valia Absoluta. Observou que um trabalhador doente custa caro. A partir desta, novas ideologias foram surgindo e com elas normas de segurança do trabalho, legislações, equipamentos mais seguros e equipamento de proteção individual (EPI).

Normalmente, os ambientes de trabalho nas indústrias madeireiras não estão adequados às Normas Regulamentadoras devido à falta de conhecimento das regulamentações e do acesso às informações sobre os procedimentos adequados para essas situações (SILVA, 1999).

As Normas Regulamentadoras (NRs) foram criadas pelo Ministério do Trabalho, por meio da Portaria 3.214/79, com o objetivo de estabelecer os requisitos técnicos e legais sobre os aspectos de segurança de saúde ocupacional. Atualmente existem 33 normas regulamentadoras. As NRs dão um direcionamento das ações e obrigações das empresas, em especial as ações de prevenção, controle e diminuição dos riscos (CAMARGO; SOUZA, 2008). 
Conforme a Alteração dada pela Portaria no 06, de 09/03/83, as normas referentes à segurança e medicina do trabalho como as NRs, são de observância obrigatória pelas empresas privadas e públicas e pelos órgãos públicos da administração direta e indireta, bem como pelos órgãos dos Poderes Legislativo e Judiciário, que possuam empregados regidos pela Consolidação das Leis do Trabalho (CLT) (GUIA TRABALHISTA, s.d.).

\subsection{ERGONOMIA NAS SERRARIAS}

Segundo o site Dicionário do Aurélio (s.d.), ergonomia é o conjunto de estudos que têm por objeto a organização do trabalho em função do fim proposto e das condições de adaptação do homem ao seu trabalho. De acordo com Prates (2007) a ergonomia de correção pode ser aplicada, objetivando-se solucionar questões de segurança, fadiga excessiva, doenças do trabalhador, quantidade e qualidade na produção. Muitas medidas podem ter baixo custo e facilidade, como mudanças de postura, inclusão de dispositivos de segurança e aumento na iluminação. Outras, já podem ser mais complexas e de custo mais elevado, como redução na carga mental ou de ruídos e substituição de máquinas inadequadas.

A indústria madeireira é um dos setores em que mais ocorrem acidentes de trabalho. As atividades que são repetidas várias vezes ao dia com falta de higiene no ambiente de trabalho, iluminação inadequada e a falta de sinalização são um risco à integridade física do trabalhador (SOUZA et al., 2002).

A ergonomia, quando colocada em prática no setor florestal, poderia evitar muitos acidentes graves. Medidas simples como o uso de Equipamentos de Proteção Individual (EPI) e Equipamentos de Proteção Coletiva (EPC) são exemplos de melhorias no setor. Porém, apesar de a NR 06 descrita em Atlas (2009) obrigar as empresas a fornecerem EPI para todos os seus 
empregados, gratuitamente, adequados ao risco, em perfeito estado de conservação e funcionamento, a falta de fiscalização é um dos principais motivos para o não uso (FALCÃO et al. 2011).

\subsection{PERFIL DOS TRABALHADORES NAS SERRARIAS}

Os trabalhadores das serrarias, geralmente são homens da zona rural, com baixo poder aquisitivo, grau de escolaridade baixo, o que dificulta o processo de qualificação e conscientização dentro das empresas, principalmente com relação ao uso de EPIs. Segundo Sobieray et al. (2007), o aumento do grau de escolaridade favorece o entendimento das orientações recebidas para o manuseio seguro das máquinas e equipamentos que o trabalhador deverá operar, além de uma maior preocupação com a integridade física e um ambiente laboral mais saudável. A presença de trabalhadores abaixo dos 40 anos, e até mesmo menores de 18 anos, é comum nas serrarias pelo simples fato de não haver fiscalização rigorosa e ser muito pesado o serviço, desrespeitando a legislação, pois, segundo Brasil (2014), em seu Artigo 403, a Lei $\mathrm{n}^{\circ} 10.097 / 2000$ determina que:

É proibido qualquer trabalho a menores de dezesseis anos de idade, salvo na condição de aprendiz, a partir dos quatorze anos.

Parágrafo único. 0 trabalho do menor não poderá ser realizado em locais prejudiciais à sua formação, ao seu desenvolvimento físico, psíquico, moral e social e em horários e locais que não permitam a frequência à escola.

\subsection{TIPOS DE RISCOS}

O trabalhador do setor florestal está em constante perigo desde o desdobro primário da tora na floresta até a comercialização, e a relação trabalho/salário/saúde está interligada. 0 
trabalho em muitas serrarias é pesado, os salários muito baixos e a saúde de muitos trabalhadores não está em boas condições, pelo fato de o ambiente de serviço não ser adequado (PIGNATI; MACHADO, 2005).

De acordo com Ministério do Trabalho e Emprego ([MTE], 2006), os níveis de riscos são estabelecidos pela Portaria no 25 de 29 de dezembro de 1994, e a Classificação dos Riscos Ambientais divide-se em cinco grupos, a saber: riscos físicos, químicos, biológicos, ergonômicos e de acidente de trabalho.

- Riscos Físicos

a. Ruído: O trabalhador exposto ao ruído intenso e prolongado na sua jornada de trabalho, sem o protetor auditivo, tem sua capacidade auditiva reduzida;

b. Temperaturas Extremas (frio ou calor): No ambiente de Trabalho, o trabalhador pode estar exposto a condições térmicas rigorosas, tanto calor quanto frio. Exemplos são trabalhos em câmaras frigoríficas e no abastecimento de fornalhas;

c. Umidade: 0 trabalhador está exposto à umidade excessiva durante sua jornada de trabalho, com grande risco para desencadear-lhe doenças;

d. Radiações Ionizantes: Exposto a materiais radioativos como é o caso do raio gama (g), ou são produzidas artificialmente em equipamentos, como é o caso dos raios $\mathrm{X}$;

e. Radiações não Ionizantes: São de natureza eletromagnética e seus efeitos dependerão de fatores como duração e intensidade de exposição, comprimento de onda de radiação, região do espectro em que se situam. Exemplos de radiação não Ionizantes são soldas e luz solar;

f. Vibrações: Ao colaborador exposto a esse tipo de risco podem resultar perturbações musculoesqueléticas, neurológicas e vasculares, além de outras patologias. Exemplos de máquinas com muita vibração são as britadeiras e os martelos picadores; 
g. Pressões Anormais: 0 colaborador estará exposto a esse tipo de risco ao realizar mergulhos profundos no mar.

- Riscos Químicos

Sendo estes representados pelas substâncias químicas que podem ser encontradas na forma líquida, gasosa e sólida, e, quando elas são absorvidas pelo organismo podem produzir reações tóxicas e danos à saúde. Possuem três vias de penetração no organismo: respiratória, cutânea e digestiva.

- Riscos Biológicos

São causados por microrganismos que são invisíveis a olho nu como, por exemplo, vírus, bactérias, parasitas, fungos, bacilos e outros. Esses microrganismos são capazes de desencadear doenças devido à contaminação e pela própria natureza do trabalho.

- Riscos Ergonômicos

São contrários às técnicas de ergonomia, as quais propõem que os ambientes de trabalho devem adaptar-se ao homem, proporcionando, assim, um bem-estar físico e psicológico ao trabalhador. Os riscos ergonômicos estão ligados também a fatores externos do ambiente e também a fatores internos, ou seja, fatores relacionados ao plano emocional do trabalhador. Ocorrem quando há a disfunção entre o indivíduo, posto de trabalho e os equipamentos. Exemplos: levantamento e transporte manual de pesos, movimentos repetitivos, trabalho de pé, esforço físico intenso, desconforto acústico, desconforto térmico, mobiliário inadequado, iluminação inadequada, postura inadequada.

- Riscos de Acidentes

Ocorrem em função das condições físicas do local de trabalho e também pela condição do processo de trabalho, técnicas impróprias e equipamentos estragados que são capazes de provocar lesões à integridade física do trabalhador. Exemplos disso são os procedimentos inadequados que envolvam a manipulação de materiais perfurantes e cortantes, máquinas sem proteção, ferramentas obsoletas. 
Lacerda (2007) apresenta, em ordem de maior ocorrência, as principais causas de acidentes nas indústrias de conversão mecânica da madeira como sendo:

a. Falta de atenção ou pressa no trabalho

b. Procedimento errado no trabalho

c. Ambiente inseguro

d. Equipamentos e máquinas com defeitos ou inadequados

e. Falta de EPIs ou seu uso incorreto

f. Equipamentos mantidos ligados, na manutenção

g. Uso incorreto de ferramentas

h. Acidente de trajeto

i. Outras causas

O autor menciona também que o primeiro local de ocorrência de acidentes são as mãos, em segundo lugar estão os olhos e o tórax, seguidos dos braços.

\subsection{EQUIPAMENTOS MAIS PERIGOSOS}

No ambiente de trabalho em uma serraria é comum observar as más condições de máquinas e equipamentos, pois esse segmento florestal é considerado rústico e insalubre. Também é evidente a falta de proteções adequadas como os equipamentos de segurança coletiva e individual. A falta de capacitação e também os treinamentos específicos poderiam evitar os acidentes de trabalho (PIGNATI; MACHADO, 2005).

Conforme esses autores, uma serraria conta com vários ambientes para processamento da madeira. Primeiramente tem-se o pátio de toras onde as toras são descarregadas e carregadas. Em seguida, a tora passa para o desdobro ou processamento mecânico primário (serra fita e serra circular), e, por fim, segue para o processamento secundário (destopadeira, plaina, fresa, lixadeira e tupia).

A serra circular e serra fita são os equipamentos que geram mutilações maiores e permanentes, podendo ser considerados os 
equipamentos mais perigosos de uma serraria. 0 trabalhador, em contato com essas máquinas em movimento, corre o risco de amputações de dedos, mãos e outras partes de membros superiores. Elas constituem o cenário mais típico desse ambiente de trabalho. Essa periculosidade está relacionada a algum grau de invalidez imposta ao trabalhador e a maior tempo de afastamento, que é geralmente mais de trinta dias, sendo que as amputações são o tipo mais grave de lesão (SOBIERAY et al. 2007).

Os altos índices de acidentes de trabalho, que têm como consequências mortes, incapacitados, amputados e muitas demandas judiciais por indenização, estão fazendo com que os juízes da Justiça do Trabalho vão a campo conhecer as empresas e suas atividades laborais. De acordo com dados oficiais, há duas décadas Mato Grosso se mantém em primeiro lugar nessa trágica estatística (SINDESSMAT, s.d.).

\subsection{EQUIPAMENTOS DE PROTEÇÃO INDIVIDUAL (EPIs)}

Os Equipamentos de Proteção Individuais (EPIs) são de extrema importância para a integridade física dos trabalhadores em uma serraria, podendo evitar graves acidentes como as amputações. Dependendo do tipo de atividade, os principais cuidados são com as seguintes partes do corpo: cabeça, membros superiores, membros inferiores, troncos e vias respiratórias.

Na busca por melhorias na área de segurança do trabalho, a Associação Nacional de Defesa Vegetal (ANDEF) e o Comitê de Boas Práticas Agrícolas (COGAP) elaboraram o Manual de Uso Correto de Equipamentos de Proteção Individual (ANDEF, 2003), que teve como principal objetivo orientar os trabalhadores da área agrícola: porém, com pequenas adaptações, os equipamentos citados a seguir podem e devem ser usados por trabalhadores das serrarias. São eles: a. Luvas: Protege as partes do corpo com maior risco de exposição, as mãos. Existem vários tipos de luvas no mercado, e a utilização 
deve ser de acordo com o tipo de formulação de produto a ser manuseado. A luva deve ser impermeável ao produto químico e, no caso das serrarias, serem resistentes, protegendo as mãos contra possíveis cortes;

b. Máscaras: Têm o objetivo de evitar a inalação de poeira, partículas de serragem suspensas no ar, partículas tóxicas através das vias respiratórias. Existem basicamente dois tipos de máscaras: sem manutenção (chamados de descartáveis), que possuem uma vida útil relativamente curta e recebem a sigla PFF (Peça Facial Filtrante), e os de baixa manutenção, que possuem filtros especiais para reposição, normalmente mais duráveis;

c. Viseira facial transparente: Protege os olhos e o rosto contra respingos durante o manuseio. A viseira deve ter a maior transparência possível e não distorcer as imagens. Deve ser revestida com viés para evitar corte. 0 suporte deve permitir que a viseira não fique em contato com o rosto do trabalhador e embace. A viseira deve proporcionar conforto ao usuário e permitir o uso simultâneo do respirador, quando for necessário;

d. Óculos transparentes: Protege somente a área dos olhos contra poeira, serragem e partículas que ficam suspensas no ar;

e. Protetor auricular: Protege os ouvidos contra ruídos dos equipamentos;

f. Avental: Produzido com material resistente a solventes orgânicos e possíveis cortes, que podem acontecer com equipamentos perfurantes;

g. Botas: devem ser impermeáveis, preferencialmente de cano alto e resistentes aos solventes orgânicos, contra possíveis quedas de objetos cortantes, perfurantes ou pesados nos pés por exemplo. É o único equipamento que não possui Certificado de Aprovação (CA).

De acordo com esse manual, os EPIs devem ser lavados, higienizados e guardados corretamente, para assegurar maior vida útil e serem mantidos separados das roupas da família. 


\subsection{MINISTÉRIO DO TRABALHO E AS LEGISLAÇÕES}

A Norma Regulamentadora no 15 (NR 15), Atividades e Operações Insalubres, Portaria 3.214 de 08 de junho de 1978 do Ministério do Trabalho e Emprego (MTE), determina que o ambiente de trabalho esteja adaptado aos funcionários, minimizando os riscos físicos, químicos e ergonômicos (ATLAS, 2009).

No Brasil (2014), a Lei no 8.213, de 24 de Julho de 1991, que dispõe sobre os Planos de Benefícios da Previdência Social e dá outras providências, no Artigo 22 determina que:

A empresa deverá comunicar o acidente do trabalho à Previdência Social até o 1o (primeiro) dia útil seguinte ao da ocorrência e, em caso de morte, de imediato, à autoridade competente, sob pena de multa variável entre o limite mínimo e o limite máximo do salário-de-contribuição, sucessivamente aumentada nas reincidências, aplicada e cobrada pela Previdência Social.

Pelo não cumprimento das obrigações, o empregador poderá vir a responder na área criminal ou cível, além de ser multado pelo Ministério do Trabalho. 0 funcionário estará sujeito a sanções trabalhistas, podendo até ser demitido por justa causa. É recomendado que o fornecimento de EPIs e os treinamentos ministrados, sejam registrados por meio de documentação apropriada, para eventuais esclarecimentos em causas trabalhistas.

A Norma Regulamentadora no 09 (NR 09) estabelece a obrigatoriedade da elaboração e implementação, por parte de todos os empregadores e instituições que admitam trabalhadores como empregados, do Programa de Prevenção de Riscos Ambientais (PPRA), visando à preservação da saúde e da integridade dos trabalhadores, por meio da antecipação, reconhecimento, avaliação e consequente controle da ocorrência de riscos ambientais existentes ou que venham a existir no ambiente de trabalho, tendo em consideração a proteção do meio ambiente e dos recursos 
naturais. As ações do PPRA devem ser desenvolvidas no âmbito de cada estabelecimento da empresa, sob a responsabilidade do empregador, com a participação dos trabalhadores, sendo sua abrangência e profundidade dependentes das características dos riscos e das necessidades de controle (ATLAS, 2009).

Os EPIs devem ser fornecidos gratuitamente para o funcionário. Esses equipamentos disponíveis no mercado são certificados pelo Certificado de Aprovação (CA), e o Ministério do Trabalho atesta sua qualidade. 0 fornecimento e a comercialização de EPI sem o CA é considerado crime, e tanto o comerciante quanto o empregador ficam sujeitos às penalidades previstas em lei (FALCÃO et al., 2011).

A Norma Regulamentadora no 06 (NR 06) estabelece que EPI é todo dispositivo ou produto, de uso individual utilizado pelo trabalhador, destinado à proteção de riscos suscetíveis de ameaçar a segurança e a saúde no trabalho. 0 EPI deverá ter o CA e, para sua comercialização, é necessária a autorização do órgão nacional competente que, no caso, é o Ministério do Trabalho e Emprego (ATLAS, 2009).

A empresa é obrigada a fornecer aos empregados, gratuitamente, EPI adequado ao risco, em perfeito estado de conservação e funcionamento (FALCÃO et al., 2011).

A Portaria da Secretaria de Inspeção do Trabalho no 247, de 12 de junho 2011, no uso das atribuições conferidas pelo Art. 14, inciso II, do Anexo I do Decreto no 5.063, de 3 de maio de 2004, e em face do disposto nos Art. 155 e 200 da Consolidação das Leis do Trabalho (CLT), aprovada pelo Decreto $\mathrm{n}^{\circ} \mathrm{5.452}$, de $1^{\circ}$ - de maio de 1943 e no Art. 2 da Portaria MTB no 3.214, de 8 de junho de 1978, visa à criação de uma Comissão Interna de Prevenção de Acidentes (CIPA), que tem como objetivo a prevenção de acidentes e doenças decorrentes do trabalho, de modo a tornar compatível, permanentemente, o trabalho com a preservação da vida e a promoção da saúde do trabalhador (MTE, 1994). 0 técnico de 
segurança do trabalho é parte importante dentro da CIPA, e o seu registro será efetuado pela Secretaria de Segurança e Saúde no Trabalho (SSST) ou pelas Delegacias Regionais do Trabalho (DRT) e concedido conforme a Norma Regulamentadora no 27 (NR 27), Registro Profissional do Técnico de Segurança do Trabalho, Ministério do Trabalho (ATLAS, 2009).

As NRs de número 10, 11, 12, 16, 17, 23, 24, 25, 26, 28 e 31, cada uma com ano diferente, também, podem ser aplicadas aos trabalhadores e empregadores das indústrias de serraria. São normas que seguem portarias da legislação vigente junto aos órgãos responsáveis como o Ministério do Trabalho.

\subsection{AS SERRARIAS DE MATO GROSSO}

Segundo Pereira et al. (2010), Mato Grosso abrigava em 2009, 20 polos madeireiros localizados a maioria no norte, noroeste e oeste do estado. As principais cidades-polos são Sinop, em primeiro lugar, seguida de Aripuanã e Juara. Esses polos são geralmente rurais e com isso pagam impostos mais baratos, ficam próximos de seus fornecedores, longe das fiscalizações e geram muitos empregos.

De acordo com Pignati e Machado (2005), Mato Grosso atualmente possui cerca de 1,6 mil empresas madeireiras, e os principais Estados que recebem a produção mato-grossense são Rio de Janeiro, São Paulo, Paraná, Santa Catarina e Rio Grande do Sul. São comercializadas mais de 140 espécies, e o valor de venda da madeira depende da negociação entre produtor e consumidor e de cada produto negociado.

Conforme Sobieray et al. (2007), no Estado de Mato Grosso, na fase de industrialização da madeira, os trabalhadores laboram em galpões/barracões, indústrias (serrarias, laminadoras, beneficiadoras e fábricas de compensado), manipulando máquinas antigas e obsoletas, não automatizadas, de baixa produtividade, 
sem as devidas proteções. Normalmente, os ambientes de trabalho nas indústrias madeireiras do Estado não estão adequados às Normas Regulamentadoras devido à falta de conhecimento das regulamentações e do acesso às informações sobre o procedimento adequado para essas situações. Em todos os ambientes da serraria, observa-se a precarização do trabalho, em graus variados, quanto mais as indústrias se afastam das sedes dos municípios, piores são as condições de trabalho/salário/saúde (PIGNATI; MACHADO, 2005).

De acordo com Tribunal Regional do Trabalho da 23a Região de Mato Grosso em 2012, os trabalhadores que mais sofrem algum tipo de acidente são do sexo masculino e estão na faixa etária entre 20 e 29 anos. Os setores com mais ocorrência de acidentes em Mato Grosso são serviços, sendo 48,3\% dos casos, indústria $(47,1 \%)$ e agropecuária $(4,6 \%)$ (SALDANHA, 2014).

\subsection{ESTATÍSTICA DOS ACIDENTES QUE OCORRERAM NO ESTADO}

Nos Quadros 1, 2 e 3, são especificados os dados estatísticos do setor, fornecidos pelo Ministério da Previdência Social, para o período de 2011-2013. 


\begin{tabular}{|c|c|c|c|c|c|c|c|}
\hline \multirow{4}{*}{$\begin{array}{c}\text { Grandes } \\
\text { Regiões e } \\
\text { Unidades da } \\
\text { Federação }\end{array}$} & \multirow{4}{*}{ Anos } & \multicolumn{6}{|c|}{$\begin{array}{l}\text { VALOR DE BENEFÍCIOS RURAIS ACIDENTÁRIOS CONCEDIDOS } \\
\text { (R\$ Mil) }\end{array}$} \\
\hline & & \multirow{3}{*}{ Total } & \multicolumn{5}{|c|}{ Grupos de Espécies } \\
\hline & & & \multirow{2}{*}{$\begin{array}{l}\text { Aposentadoria } \\
\text { por Invalidez }\end{array}$} & \multirow{2}{*}{$\begin{array}{c}\text { Pensão por } \\
\text { Morte }\end{array}$} & \multicolumn{3}{|c|}{\begin{tabular}{|c|} 
Auxílios \\
\end{tabular}} \\
\hline & & & & & Total & Doença & Acidente \\
\hline \multirow{3}{*}{ BRASIL } & 2011 & 12.420 & 462 & 14 & 11.944 & 11.764 & 181 \\
\hline & 2012 & 12.664 & 492 & 15 & 12.157 & 11.959 & 198 \\
\hline & 2013 & 13.625 & 524 & 9 & 13.091 & 12.834 & 257 \\
\hline \multirow{3}{*}{ CENTRO-OESTE } & 2011 & 222 & 12 & 2 & 209 & 205 & 4 \\
\hline & 2012 & 274 & 12 & 4 & 258 & 254 & 4 \\
\hline & 2013 & 298 & 15 & 1 & 281 & 276 & 4 \\
\hline \multirow{3}{*}{ MATO GROSSO } & 2011 & 122 & 8 & - & 114 & 112 & 3 \\
\hline & 2012 & 119 & 5 & - & 114 & 113 & 1 \\
\hline & 2013 & 115 & 7 & 1 & 107 & 106 & 2 \\
\hline
\end{tabular}

Quadro 1 - Benefícios rurais acidentários conforme a região brasileira.

Fonte: Adaptado (BRASIL, 2014).

Considerando-se que boa parte das serrarias estão afastadas da cidade, o Quadro 1 mostra que nos benefícios rurais acidentários concedidos como aposentadoria por invalidez, doenças e acidentes houve um aumento significativo de 2012 para 2013, isso no Brasil, considerando o total. No Centro-Oeste, a aposentadoria por invalidez e por doença aumentou de 2012 para 2013; se considerar somente Mato Grosso, de 2012 para 2013, a aposentaria por invalidez e acidente aumentaram. 


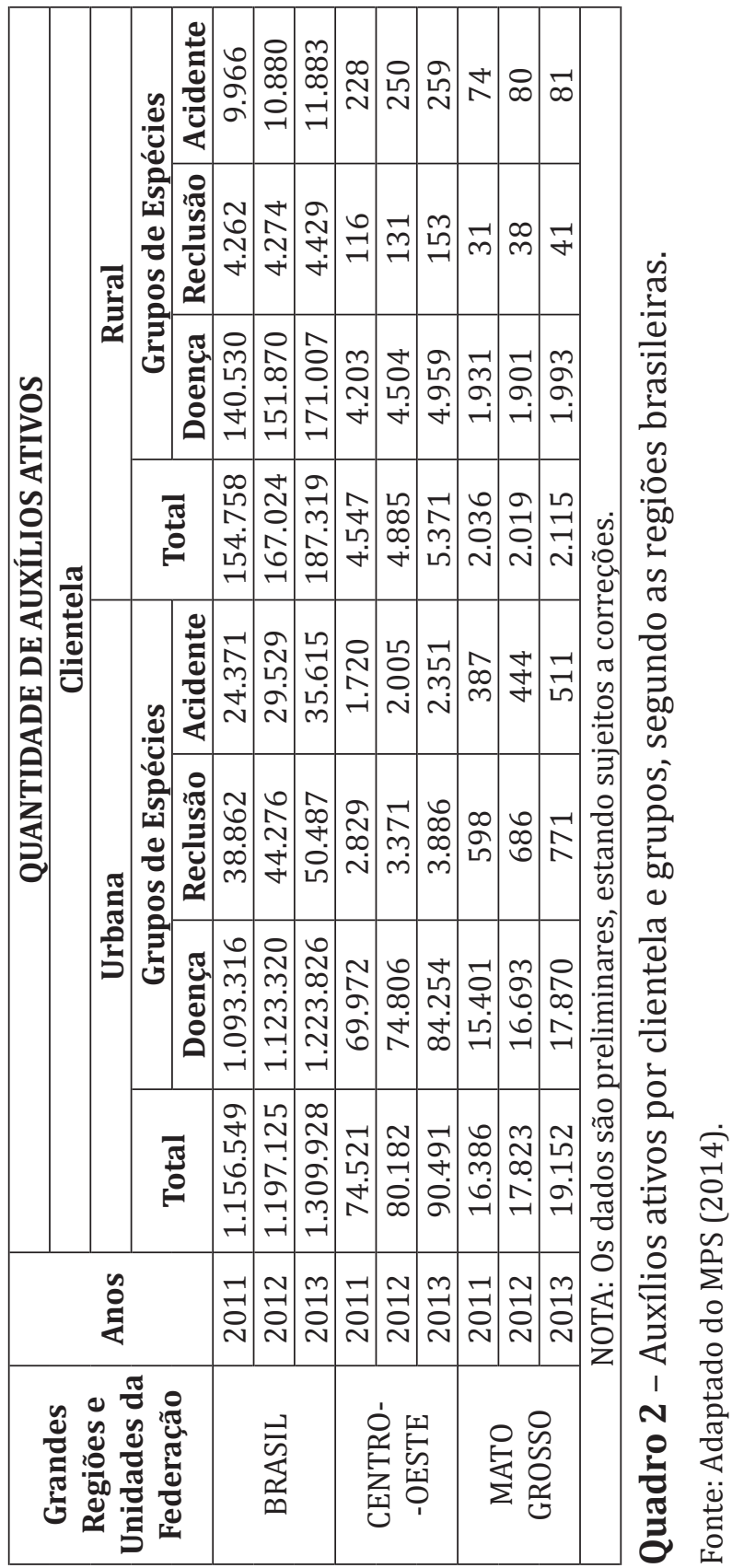


Observa-se no Quadro 2, que a quantidade de auxílios ativos que são as pessoas que recebem o benefício, quando comparando a clientela rural e urbana, o trabalhador do setor madeireiro se encaixa em ambos os ambientes. No Brasil auxílios como de doenças, reclusão, acidente tanto rural quanto urbano aumentou de 2012 para 2013. No Centro-Oeste, no caso Mato Grosso, de 2012 para 2013 também houve um aumento em todos os níveis de auxílio tanto para urbano quanto rural.

A quantidade de acidentes de trabalho nas indústrias obteve uma redução de 2012 para 2013. Os acidentes que foram registrados na Comunicação de Acidente de Trabalho (CAT) aumentaram de 2012 para 2013 e consequentemente sem o CAT reduziu (Quadro 3). Isso mostra, talvez, a preocupação do empresário com seu trabalhador. Esta aplicação possibilita cadastrar a "Comunicação de Acidente de Trabalho - CAT" junto ao INSS, para facilitar e agilizar o registro dos Acidentes de Trabalho e das Doenças Ocupacionais, pelo Empregador, havendo ou não afastamento do trabalho por parte do acidentado.

\begin{tabular}{|c|c|c|c|c|c|c|c|}
\hline \multirow{4}{*}{$\begin{array}{c}\text { Setor de } \\
\text { Atividade } \\
\text { Econômica (1) }\end{array}$} & \multirow{4}{*}{ Anos } & \multicolumn{6}{|c|}{ QUANTIDADE DE ACIDENTES DE TRABALHO } \\
\hline & & \multirow{3}{*}{ Total } & \multicolumn{4}{|c|}{ Com CAT Registrada } & \multirow{3}{*}{$\begin{array}{c}\text { Sem CAT } \\
\text { Registrada }\end{array}$} \\
\hline & & & \multirow[b]{2}{*}{ Total } & \multicolumn{3}{|c|}{ Motivo } & \\
\hline & & & & Típico & Trajeto & $\begin{array}{c}\text { Doença do } \\
\text { Trabalho }\end{array}$ & \\
\hline \multirow{3}{*}{ TOTAL } & 2011 & 720.629 & 543.889 & 426.153 & 100.897 & 16.839 & 176.740 \\
\hline & 2012 & 713.984 & 546.222 & 426.284 & 103.040 & 16.898 & 167.762 \\
\hline & 2013 & 717.911 & 559.081 & 432.254 & 111.601 & 15.226 & 158.830 \\
\hline \multirow{3}{*}{ Indústria } & 2011 & 316.627 & 256.466 & 214.923 & 32.802 & 8.741 & 60.161 \\
\hline & 2012 & 310.988 & 252.100 & 211.245 & 32.495 & 8.360 & 58.888 \\
\hline & 2013 & 308.816 & 252.960 & 210.397 & 35.242 & 7.321 & 55.856 \\
\hline \multirow{3}{*}{$\begin{array}{l}\text { Indústria de } \\
\text { transformação }\end{array}$} & 2011 & 232.471 & 189.251 & 158.167 & 23.709 & 7.375 & 43.220 \\
\hline & 2012 & 222.073 & 181.052 & 151.102 & 22.876 & 7.074 & 41.021 \\
\hline & 2013 & 222.473 & 182.845 & 151.908 & 24.922 & 6.015 & 39.628 \\
\hline
\end{tabular}

Quadro 3 - Acidentes de trabalho por situação de registro e motivo conforme o setor de atividade econômica.

Fonte: Adaptado (BRASIL, 2014). 
De acordo com Ultramari et al. (2012), os problemas de acidentes de trabalho não são de caráter individual, mas sim um problema social e econômico para todo o país, pois gera despesas com médicos e hospital ao Sistema Único de Saúde (SUS). Além disso, tem também o custo social que é o impacto gerado sobre a saúde e vida do trabalhador e seus familiares. No que tange à dívida federal, o estado tem custos com o Instituto Nacional de Seguridade Social (INSS) por causa dos trabalhadores afastados pelos acidentes de trabalho sofridos. Vários auxílios são disponibilizados ao trabalhador acidentado ou aos seus dependentes tais como: auxílio doença ou auxílio acidente do trabalho, aposentadorias por invalidez e precoces, pensões vitalícias.

\subsection{SITUAÇÃO DAS SERRARIAS NO BRASIL E NO MUNDO}

A grande discussão sobre o segmento madeireiro no Brasil se limitava às questões ambientais, ficando de lado alguns fatores essenciais para o desenvolvimento do setor, como a formação de mão de obra e a segurança desses trabalhadores (AMARAL et al., 2005).

A maioria dos acidentes na exploração da madeira, alguns dos quais são fatais, ocorre na etapa do corte de árvores. Segundo Amaral et al. (1998), nas atividades de extração, desdobramento, beneficiamento e industrialização da madeira é que se sucedem inúmeros acidentes, com alto índice de amputação devido à utilização de máquinas em precárias condições de uso.

Em 1994, após a abertura da economia, ocorreram maiores avanços no Brasil com relação à colheita florestal. Desde então, esse processo vem-se mostrando irreversível, segundo Burla (2008). As empresas, de maneira mais intensiva, começaram a mecanização do trabalho, devido aumento do custo de mão de obra, necessidade de executar o trabalho de forma mais ergonômica, reduzindo os índices de acidentes, com maior eficiência e 
diminuindo os custos de produção (MACHADO, 2002). Ainda hoje predomina o trabalho manual na colheita florestal, visto que a introdução de novas técnicas e equipamentos especializados é um processo lento e restrito. As empresas que estão adotando tais práticas obtêm resultados altamente satisfatórios, porém o grau de modernização da colheita depende da evolução da própria indústria de máquinas e equipamentos (DANIEL, 2006).

0 alto rendimento das empresas madeireiras dos Estados Unidos mostra que a utilização de tecnologia avançada, a atenção voltada para a redução de desperdícios, o armazenamento de toras de forma adequada, o uso de equipamentos de seguranças, as normas trabalhistas rigorosas são fatores de extrema importância para contribuir com esse alto rendimento. Uma causa importante da baixa porcentagem de madeira processada para exportação são os padrões estritos de qualidade impostos, os quais resultam na rejeição da madeira serrada com defeitos menores (ARAÚJO, 2014).

Segundo estudo realizado pelo BNDES (1995), as serrarias possuíam baixa capacidade produtiva, baixa produtividade, baixa qualidade dos produtos, pouca modernização industrial e defasagem sobre as técnicas atuais de gestão empresarial e produtiva. Atualmente, as serrarias que possuem melhores índices de conversão de madeira serrada possuem equipamentos modernos e geralmente importados, originários principalmente de países europeus como Alemanha e França ou da América do Norte, principalmente do Canadá, onde a cultura da usinagem da madeira para os mais diversos usos é muito antiga e bem desenvolvida.

Um bom exemplo a ser seguido é aquele realizado pelas empresas madeireiras do Chile, que, atualmente, têm uma posição de destaque no mercado da madeira. Por ser um país com território pequeno e com depressões naturais que dificultam e encarece o plantio e a colheita de madeira, as empresas chilenas investiram em capacitação da mão de obra, em tecnologia, e hoje 
possuem produtos como madeira serrada, molduras e chapas de madeira, com qualidade reconhecida mundialmente. Houve um crescimento de $322 \%$ em quinze anos, e hoje exporta madeira para cinco continentes. Um dos motivos desse crescimento foi o contato direto com o cliente, através da eliminação do agente de exportação (PEREIRA, 2011).

Segundo Blaurepaire (2003), o tratado da União Europeia prevê que a Comunidade Europeia deve favorecer a promoção de um crescimento durável e não inflacionário, com um alto nível de proteção e de melhoramento ambiental. Para esse fim, a comunidade possui uma política em matéria de meio ambiente, cujos princípios estão definidos no artigo 174 do tratado da União Europeia. A política da comunidade, na área ambiental, possui os seguintes objetivos:

a) a preservação, a proteção e o melhoramento da qualidade ambiental;

b) a proteção da saúde das pessoas;

c) a utilização prudente e racional dos recursos naturais;

d) a promoção, sob o plano regional, de medidas destinadas a enfrentar os problemas regionais ou planetários do meio ambiente.

0 principal problema das indústrias madeireiras e moveleiras, em termos de segurança, conforme Veras (2006), é a falta de investimentos por parte da empresa na proteção adequada de máquinas. 0 autor ainda explica que a legislação que proíbe a venda de máquinas sem equipamentos de proteção, vem sendo descumprida, como forma de baratear os custos de aquisição. Para ele, não se justifica o argumento da dificuldade de importação, pois já existem máquinas nacionais seguras. Outro ponto crítico da indústria madeireira é relacionado à falta de qualificação, sendo que a maior parte dos funcionários é treinada por profissionais mais antigos. 


\section{CONCLUSÕES}

0 perfil de acidentes dentro das indústrias madeireiras segue um protótipo para todo o País, ou seja, não se diferencia de acordo com seus locais de origem.

A qualificação da mão de obra operacional, bem como a modernização do parque industrial, poderá auxiliar na minimização dos acidentes de trabalho dentro do setor.

As serras circulares e de fita são os equipamentos que mais causam acidentes dentro das serrarias.

O Estado de Mato Grosso, apesar de ser um grande polo madeireiro, não dispõe de normas regulamentadoras e disciplinadoras sobre segurança de trabalho em serrarias.

Os acidentes de trabalho geram grandes custos para os cofres do governo e empresários.

\section{RECOMENDAÇÕES}

- Recomenda-se fazer um levantamento "in loco", dentro dos diferentes polos madeireiros do País, para verificar a situação real de trabalho da mão de obra do setor, evitando-se assim tantas perdas humanas e econômicas dentro dessas indústrias.

- As empresas devem realizar cursos de treinamentos periódicos para seus trabalhadores, a fim de se evitar tantos acidentes.

\section{REFERÊNCIAS}

AMARAL, A. E.; KOURY, C. S.; VASCONCELOS, G. N.; ROCHA, E. L. A. F. Segurança, saúde do trabalhador e meio ambiente nas atividades florestais e madeireiras. "Prevenção e proteção com máquinas". In: CONGRESSO NACIONAL SOBRE CONDIÇÕES E MEIO AMBIENTE DO TRABALHO NA INDÚSTRIA DA CONSTRUÇÃO, V., SEMINÁRIO SOBRE CONDIÇÕES E MEIO AMBIENTE DE TRABALHO NA INDÚSTRIA DA CONSTRUÇÃO NOS PAÍSES DO MERCOSUL, III., 23-26 out. 2005, São Paulo. Anais... São Paulo: FUNDACENTRO, 2005. 
AMARAL, P. H. C.; VERÍSSIMO, J. A. O; BARRETO, P. G.; VIDAL, E. J. S. Floresta para sempre: um manual para produção de madeira na Amazônia. Belém: Imazon, 1998. p. 130.

ARAÚJO, Rosanne Teixeira de. Alternativas Sustentáveis de Uso da Madeira na Construção Civil. Revista da Madeira, Curitiba, n. 139, maio 2014. Disponível em: <http://www.remade.com.br/br/ revistadamadeira_materia.php?num $=1744 \&$ subject $=$ CConstr $\%$ E7 $\%$ E3o\%20Civil\&title=Alternativas $\% 20$ sustent $\%$ E1veis $\% 20 \mathrm{de} \% 20$ uso $\% 22$ da $\% 20$ madeira $\% 20$ na $\% 20$ constru $\%$ E $\%$ E3o\%20 civil >. Acesso em: 29 jan. 2015.

ASSOCIAÇÃO NACIONAL DE DEFESA VEGETAL (ANDEF). Manual de uso correto de equipamentos de proteção individual - ANDEF. Campinas: Linea Creativa, 2003.

ATLAS - Manuais de Legislações. In: Segurança e Medicina do Trabalho. 63. ed. São Paulo: Atlas, 2009. p. 142-224.

BANCO NACIONAL DO DESENVOLVIMENTO (BNDES). Relatos setoriais produtos florestais - madeira em tora, madeira serrada e painéis. Panorama 1980/1992. Brasília, DF: BNDES, 1995. 41 p.

BLAUREPAIRE, E. Recyclage de produits em fin de vie. Paris: Association Française de Normalisation (AFNOR), 2003.

BRASIL. Decreto Lei no 5.452, de $1^{\text {o }}$ de maio de 1943. Aprova a Consolidação das Leis do Trabalho. Jusbrasil, Rio de Janeiro, [s.d.]. Disponível em: <http://www.jusbrasil.com.br/topicos/10720275/ artigo-403-do-decreto-lei-n-5452-de-01-de-maio-de-1943>. Acesso em: 22 set. 2014.

. Lei 10.097, de 19 de dezembro de 2000. Altera dispositivos da Consolidação das Leis do Trabalho - CLT, aprovada pelo Decreto-Lei no 5.452, de 1ํo de maio de 1943. Jusbrasil, Brasília, DF [s.d.]. Disponível em: <http://www.jusbrasil.com.br/busca?q=Art.+1+da+Lei+do+Apre ndiz+-+Lei+10097\%2F00>. Acesso em: 22 set. 2014.

. Lei 8.213, de 24 de julho de 1991. Dispõe sobre os Planos de Benefícios da Previdência Social e dá outras providências. Jusbrasil, Rio de Janeiro, [s.d.]. Disponível em: <http://www.jusbrasil.com.br/busca? q=Art.+22+da+Lei+8213\%2F91>. Acesso em: 23 set. 2014. 
Ministério da Previdência Social (MPS), 2014. Disponível em: <http://www.previdencia.gov.br/estatisticas/>. Acesso em: 27 set. 2014.

. Ministério do Trabalho e Emprego (MTE), 2006. Disponível em <http://www.portal.mte.gov.br/portal-mte>. Acesso em: 02 out. 2014.

. Ministério do Trabalho e Emprego (MTE), 1994. Disponível em: <http://www.portal.mte.gov.br/portal-mte>. Acesso em: 2 out. 2014. BURLA, Everson. Avaliação técnica e econômica do "Harvester" na colheita do eucalipto. 2008. Dissertação (Mestrado em Engenharia Agrícola) - Universidade Federal de Viçosa, Viçosa, MG, 2008.

CAMARGO, M.; SOUZA, H. E. L. Segurança do trabalho: um estudo de caso de uma empresa madeireira. Revista Eletrônica Lato Sensu UNICENTRO, Paraná, Ed. 6, p. 2-15, 2008.

DANIEL, O. Silvicultura sustentável: métodos e práticas. Dourados: UFGD, 2006.

DICIONÁRIO DO AURÉLIO, [s.d.]. Disponível em: <http://www. dicionariodoaurelio.com/ergonomia>. Acesso em: 20 out. 2014.

FALCÃO, A.; DIAS, A.; SALDANHA, M. F.; FRANZ, L. A. S. Análise ergonômica do trabalho: o caso de uma serraria na Metade Sul do Rio Grande do Sul. GEPROS. Gestão da Produção, Operações e Sistemas, ano 6, n. 4, p. 59-73, out./dez. 2011.

GUIA Trabalhista. Normas regulamentadoras - segurança e saúde do trabalho, [s.d.]. Disponível em: <www.guiatrabalhista.com.br/ legislacao/nrs.htm>. Acesso em: 02 out. 2014.

INSTITUTO DO HOMEM E MEIO AMBIENTE DA AMAZÔNIA (IMAZON). Transparência Florestal da Amazônia Legal. Boletim do desmatamento da Amazônia Legal, Belém, ago. 2014. Disponível em: <http:// site1378233601.provisorio.ws/PDFimazon/Portugues/transparencia_ florestal/amazonia_legal/SAD-Agosto_2014.pdf>.Acesso em: 20 set. 2014.

LACERDA, E. A segurança do trabalho na indústria de conversão mecânica da madeira. 3. ed. Manual. Curitiba: UFPR, 2007. 34 p.

MACHADO, C. C. Colheita florestal. Viçosa, MG: UFV, 2002. 
MARX, K. O Capital. Crítica da economia política. Tradução de Círculo do Livro Ltda. São Paulo: Editora Nova Cultural Ltda., 1996. (Série Os economistas, v. 1-6, Livros 1-3).

PEREIRA, M. C. M. Proposta de boas práticas de fabricação para a indústria de madeira serrada baseada nos requisitos da ISSO 9001 e no Sistema 5S. 2011. 61 f. Trabalho de Conclusão de Curso (Especialização em Engenharia de Produção) - Universidade de São Paulo, Escola de Engenharia de São Carlos, São Carlos, SP. 2011.

PEREIRA, D.; SANTOS, D.; VEDOVETO, M., GUIMARÃES, J.; VERÍSSIMO, A. Fatos Florestais da Amazônia 2010. Belém: Imazon, 2010. p. 39-43.

PIGNATI, W. A.; MACHADO, J. M. H. Riscos e agravos à saúde e à vida dos trabalhadores das indústrias madeireiras de Mato Grosso. Ciência Saúde Coletiva, Rio de Janeiro, v. 10, n. 4, out./dez. 2005.

PRATES, G. A. Reflexão sobre o uso da ergonomia aliado à tecnologia: propulsores do aumento da produtividade e da qualidade de vida no trabalho. RACRE - Revista de Administração, Espírito Santo do Pinhal, SP, v. 07, n. 11, jan./dez. 2007.

SALDANHA, G. Números de acidentes no trabalho em Rondonópolis são alarmantes. A Tribuna - Mato Grosso, Rondonópolis, 8 jan. 2014. Disponível em: <http://www.atribunamt.com.br/2014/01/numerosde-acidentes-no-trabalho-em-rondonopolis-sao-alarmantes/>. Acesso em: 20 set. 2014 .

SILVA, G. M. Introdução à segurança do trabalho. Apostila. Centro Federal de Educação Tecnológica de Minas Gerais (CEFT-MG), 2008. 123p.

SILVA, K. R. Análise de fatores ergonômicos em marcenarias no munícipio de Viçosa, MG. 1999. 96 f. Dissertação (Mestrado em Ciência Florestal) - Universidade Federal de Viçosa, Viçosa, MG, 1999.

SINDICATO DOS ESTABELECIMENTOS DE SERVIÇOS DE SAÚDE DO ESTADO DE MATO GROSSO (SINDESSMAT), [s.d.]. Disponível em: <http:// www.sindessmat.com.br/portal/index.php/2014-03-08-20-0644/ item/124-mt-e-lider-em-acidente-de-trabalho>. Acesso em: 20 set. 2014.

SISTEMA FEDERAÇÃO DAS INDÚSTRIAS NO ESTADO DE MATO GROSSO (FIEMT), [s.d.]. Disponível em: <http://www.fiemt.com.br/sindicatos. php>. Acesso em: 20 out. 2014. 
SOBIERAY, T. N. C.; NOGUEIRA, M. C. J. A.; DURANTE, L. C.; LAMBERT, J. A. Um estudo sobre o uso de equipamentos de proteção coletiva como prevenção de acidentes em indústrias madeireiras de Mato Grosso. Revista Eletrônica do Mestrado em Educação Ambiental, Rio Grande, v. 18, jan./jul. 2007.

SOUZA, V.; BLANK, V. L. G.; CALVO, M. C. M. Cenários típicos de lesões decorrentes de acidentes de trabalho na indústria madeireira. Revista de Saúde Pública, São Paulo, v. 36, n. 6, p. 702-708, dez. 2002.

ULTRAMARI, A. V.; SILVA, A. M. C.; PIGNATI, W. A. Ambiente de trabalho: influência da produção florestal sobre os acidentes do trabalho no estado de Mato Grosso. Cadernos Saúde Coletiva, Rio de Janeiro, v. 20, n. 1, p. 25-31, 2012.

VERAS, D. Madeira e sangue: perfil da indústria moveleira. Netvisao, 2006. Disponível em: <http://clientes.netvisao.pt/alme0020/historia_ madeiras.htm>. Acesso em: 15 jan. 2015. 
